\title{
Melanoma Cell Adhesion Molecule Expressing Helper T Cells in CNS Inflammatory Demyelinating Diseases
}

Ryotaro Ikeguchi, MD, PhD, Yuko Shimizu, MD, PhD, Akihiro Kondo, MD, Natsuki Kanda, MD, Hayato So, MD, Haruka Kojima, MD, and Kazuo Kitagawa, MD, PhD

Neurol Neuroimmunol Neuroinflamm 2021;8:e1069. doi:10.1212/NXI.0000000000001069
Correspondence

Dr. Shimizu

shimizu.yuko@twmu.ac.jp

\section{Abstract}

\section{Background and Objective}

To elucidate the relationship between melanoma cell adhesion molecule (MCAM)expressing lymphocytes and pathogenesis of CNS inflammatory demyelinating diseases (IDDs).

\section{Methods}

Patients with multiple sclerosis (MS) $(\mathrm{n}=72)$ and neuromyelitis optica spectrum disorder (NMOSD, $\mathrm{n}=29$ ) were included. We analyzed the frequency and absolute numbers of $\mathrm{MCAM}^{+}$lymphocytes (memory helper $\mathrm{T}[\mathrm{mTh}]$ cells, naive helper $\mathrm{T}$ cells, $\mathrm{CD} 8^{+} \mathrm{T}$ cells, and $B$ cells) in the peripheral blood (PB) and the CSF of patients with MS and NMOSD, treated with/without disease-modifying drugs (DMDs) or steroids, using flow cytometry.

\section{Results}

The frequency of $\mathrm{MCAM}^{+}$cells was higher in the mTh cell subset than that in other lymphocyte subsets. A significant increase in the frequency and the absolute number of $\mathrm{MCAM}^{+} \mathrm{mTh}$ cells was observed in the PB of patients with NMOSD, whereas no increase was observed in the PB of patients with MS. The frequency of $\mathrm{CSF} \mathrm{MCAM}^{+} \mathrm{mTh}$ cells was higher in relapsing patients with MS and NMOSD than that in the control group. Although there was no difference in the frequencies of $\mathrm{MCAM}^{+}$lymphocytes among the DMD-treated groups, fingolimod decreased the absolute number of $\mathrm{MCAM}^{+}$lymphocytes.

\section{Discussion}

$\mathrm{MCAM}^{+} \mathrm{mTh}$ cells were elevated in the CSF of relapsing patients with MS and in both the PB and CSF of patients with NMOSD. These results indicate that MCAM contributes to the pathogenesis of MS and NMOSD through different mechanisms. MCAM could be a therapeutic target of CNS IDDs, and further study is needed to elucidate the underlying mechanism of MCAM in CNS IDD pathogenesis. 


\section{Glossary}

ANOVA = analysis of variance; $\mathbf{D M D}=$ disease-modifying drug; $\mathbf{D M F}=$ dimethyl fumarate; $\mathbf{E A E}=$ experimental autoimmune encephalomyelitis; EDSS = Expanded Disability Status Scale; FTY = fingolimod; HC = healthy control; IDD = inflammatory demyelinating disease; IFN = interferon; IL = interleukin; $\mathbf{M C A M}=$ melanoma cell adhesion molecule; $\mathbf{M G}=$ myasthenia gravis; $\mathbf{m T h}$ cell $=$ memory helper $\mathrm{T}$ cell; $\mathbf{N I N D}=$ noninflammatory neurologic disorder; $\mathrm{NMOSD}=$ neuromyelitis optica spectrum disorder; NTZ = natalizumab; PB = peripheral blood; PBMC = PB mononuclear cells; PSL = prednisolone; RA = rheumatoid arthritis; Th1 $=$ T helper $1 ;$ Th17 $=$ T helper 17 .

Multiple sclerosis (MS) is the most common CNS inflammatory demyelinating disease (IDD). Clinical and experimental evidence suggests an autoimmune-mediated etiology for MS. ${ }^{1,2}$ Previous studies have suggested that $\mathrm{T}$ helper 1 (Th1) and T helper 17 (Th17) cells are pathogenic in MS. ${ }^{3-6}$ Adhesion molecules are essential for the migration of these lymphocytes to the CNS. In addition, they play an important role in MS pathogenesis and are therapeutic targets for MS. For example, natalizumab (NTZ) is one of the most effective disease-modifying drugs (DMDs) used for MS treatment. NTZ targets the adhesion molecule $\alpha 4$-integrin subunit of very late antigen- 4 on Th cells, ${ }^{7}$ consequently blocking the adhesion of Th cells to blood vessels in the CNS and preventing their migration into the CNS. Melanoma cell adhesion molecule (MCAM)-expressing T cells reportedly consist of an interleukin (IL)-17-producing pathogenic Th cell subset in MS, experimental autoimmune encephalomyelitis (EAE), and other inflammatory diseases. ${ }^{8-13}$ In addition, the frequency of $\mathrm{MCAM}^{+} \mathrm{Th}$ cells increases in the peripheral blood (PB) and the CSF and accumulates in CNS lesions of patients with MS. An MCAM blockade ameliorates EAE severity. ${ }^{11,14}$ Therefore, the role of MCAM in CNS IDD pathogenesis is increasingly attracting attention. However, studies on MCAM in MS or neuromyelitis optica spectrum disorder (NMOSD) are limited.

In this study, we evaluated the frequency and the absolute number of $\mathrm{MCAM}^{+}$lymphocytes in the PB and the CSF of CNS IDDs to elucidate the relationship between MCAMexpressing lymphocytes and the pathogenesis of CNS IDDs.

\section{Methods}

\section{Participants}

In total, 72 patients with MS and 29 with NMOSD were included in this study. In addition, 23 patients with myasthenia gravis (MG), 34 with noninflammatory neurologic disorder (NIND), and 25 healthy subjects ( $\mathrm{HCs}$ ) were included as the controls. NIND included stroke, chronic headache, neurodegenerative disorders, and epilepsy. The patient profile among patients with MS, NMOSD, MG, NIND, and HCs was similar, as shown in Table 1. The mean ages of patients with MS, NMOSD, MG, NIND, and HCs were 42.0 (range 19-74), 51.5 (27-77), 52.8 (20-74), 49.0 (18-82), and 43.1 (25-80) years, respectively, and the male-to-female ratios were $26 / 46,5 / 24,9 / 14,11 / 23$, and $11 /$ 14 , respectively. The relapse phase (active) to remission (stable) phase ratios in MS, NMOSD, and MG were 30/36 (the other 6 patients presented with secondary progressive MS), $14 / 15$, and $15 / 8$, respectively, and the disease duration was $12.5 \pm 8.4,10.4 \pm$ 10.4 , and $8.9 \pm 12.5$ (mean \pm SD) years, respectively. We also compared MCAM expression in each lymphocyte subset among the untreated patients with MS $(\mathrm{n}=25)$ and those treated with different DMDs (interferon [IFN]- $\beta$ [ $n=12]$, dimethyl fumarate $[\mathrm{DMF}][\mathrm{n}=11]$, fingolimod [FTY] $[\mathrm{n}=18]$, and NTZ $[\mathrm{n}=6])$. At the time of examination, 25 of 29 patients with NMOSD and 19 of 23 patients with MG were being treated with oral prednisolone (PSL; mean dose, $12.3 \mathrm{mg} /$ day and $10.6 \mathrm{mg} /$ day, respectively). Patients with NIND did not receive any immunotherapy. None of these patients had received pulse steroid therapy, IV immunoglobulin, or plasma exchange $>1$ month before blood sampling. We analyzed the MCAM expression $>3$ months after initiation of any DMDs. CSF and PB paired samples were obtained from 10 patients with MS (8 relapse and 2 remission), 6 with NMOSD (4 relapse and 2 remission), and 15 with NIND. The diagnoses of MS and NMOSD were established according to the $2010 \mathrm{McD}$ onald criteria and the international consensus diagnostic criteria for NMOSD, respectively. ${ }^{15,16}$ All patients were recruited from Tokyo Women's Medical University Hospital, Japan.

\section{Standard Protocol Approvals, Registrations, and Patient Consents}

This study was approved by the ethics committee of Tokyo Women's Medical University School of Medicine. Written informed consent was obtained from each participant. This is a cross-sectional study conducted between February 2016 and September 2020.

\section{Cell Preparation and Flow Cytometry}

PB mononuclear cells (PBMCs) were freshly isolated through density-gradient centrifugation using Ficoll-Paque Plus (GE Healthcare, Oakville, ON, Canada) and immediately stored at $-80^{\circ} \mathrm{C}$, until the time of analysis. They were stained against cell surface antigens, according to the manufacturer's instructions. Fluorescent-conjugated monoclonal antibodies (mAbs) and isotype controls used in this study were as follows: CD3-PerCpCy5.5, CD4-PE-Cy7, CD45RA-Pacific blue, CD19-APC-Cy7, MCAM (CD146)-APC (clone P1H12), a4-integrin (CD49d)$\mathrm{PE}$, and mouse IgG1к-APC (BioLegend, San Diego, CA); CD8-fluorescein isothiocyanate (Beckman Coulter, Brea, CA); and IgG1к-PE (BD Pharmingen, San Jose, CA). Each lymphocyte subset was defined like in Figure 1 and Table 2. CSF cells were stained directly with the above-mentioned Abs. After incubation, cells were washed and resuspended in phosphate-buffered saline. 
Table 1 Demographic and Clinical Characteristics of CNS IDDs and Controls

\begin{tabular}{|c|c|c|c|c|c|}
\hline & $H C(n=25)$ & MS $(n=72)$ & NMOSD $(n=29)$ & MG $(n=23)$ & NIND $(n=34)$ \\
\hline Female, $\mathbf{n}(\%)$ & $14(56)$ & $46(64)$ & $24(83)$ & $14(61)$ & $23(68)$ \\
\hline Age, mean (range), y & $43(25-80)$ & $42(19-74)$ & $51(27-77)$ & $53(20-74)$ & $49(18-82)$ \\
\hline Disease duration, mean (SD), y & - & $12.5(8.4)$ & $10.4(10.4)$ & $8.9(12.5)$ & - \\
\hline Phase (relapse/remission/progressive), $n$ & - & $30 / 36 / 6$ & $14 / 15 / 0$ & $15 / 8 / 0$ & - \\
\hline EDSS score, median (range) & - & $3.5(0-9.0)$ & $5.0(1.0-8.0)$ & - & - \\
\hline \multicolumn{6}{|l|}{ Treatment, $\mathbf{n}$} \\
\hline IFN- $\beta$ & - & 12 & - & - & - \\
\hline DMF & - & 11 & - & - & - \\
\hline FTY & - & 18 & - & - & - \\
\hline NTZ & - & 6 & - & - & - \\
\hline PSL & - & 0 & 25 & 19 & - \\
\hline Immunosuppressant $^{a}$ & - & 0 & 3 & 11 & - \\
\hline Untreated & - & 25 & 4 & 3 & - \\
\hline
\end{tabular}

Abbreviations: $\mathrm{DMF}=$ dimethyl fumarate; EDSS = Expanded Disability Status Scale; FTY = fingolimod; $\mathrm{HC}=$ healthy control; IDD = inflammatory demyelinating disease; IFN = interferon; MG = myasthenia gravis; NIND = noninflammatory neurologic disorder; NMOSD = neuromyelitis optica spectrum disorder; NTZ = natalizumab; PSL = prednisolone.

${ }^{a}$ Immunosuppressant includes tacrolimus (1 with NMOSD and 9 with MG), azathioprine (2 with NMOSD), and cyclosporine (2 with MG).

Cells were then measured using a Gallios Flow Cytometer (Beckman Coulter) and analyzed using Kaluza Analysis Software (Beckman Coulter). The absolute number of each lymphocyte subset was obtained by the dual-platform method.

\section{Statistical Analysis}

Statistical analyses were performed with GraphPad Prism 7 (GraphPad Software, San Diego, CA). An unpaired $t$ test or Mann-Whitney $U$ test was used, as appropriate, for statistical analyses of data between 2 groups. One-way analysis of variance (ANOVA) or the Kruskal-Wallis test was used, as appropriate, to compare data from more than 2 groups. If the one-way ANOVA or Kruskal-Wallis test results were significant, post hoc analyses were performed using the Tukey test or the Dunn multiple comparison test, respectively. Correlations between 2 variables were examined using linear regression analyses. Statistical significance was indicated at $p$ value $<0.05$.

\section{Data Availability}

Anonymized data are available from the corresponding author on reasonable request from any qualified investigator for purposes of replicating the procedures and results.

\section{Results}

\section{The Frequency and Absolute Number of MCAM $^{+}$Lymphocytes in Patients With NMOSD Increased}

First, we analyzed the frequency of $\mathrm{MCAM}^{+}$cells in each lymphocyte subset (mTh cells, naive Th [nTh] cells,
$\mathrm{CD}^{+} \mathrm{T}$ cells, and $\mathrm{B}$ cells) in the PB (Figure 1, A and B) of all 183 patients and HCs. Consistent with the results of previous studies, the frequency of $\mathrm{MCAM}^{+}$lymphocytes was higher in $\mathrm{mTh}$ cells than that in other lymphocyte subsets, ${ }^{10,12}$ and most $\mathrm{MCAM}^{+}$cells coexpressed CD49d. ${ }^{17}$ By contrast, only a

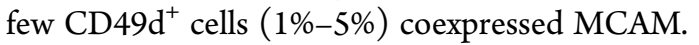

Next, we compared the frequency and the absolute number of $\mathrm{MCAM}^{+}$cells in each lymphocyte subset in the $\mathrm{PB}$ among the disease groups. FTY- and DMF-treated patients with MS were excluded from the absolute number analysis because treatment with these DMDs modified the number of lymphocytes, as described in eTables 1 and 2, links.lww. com/NXI/A559. In addition, the absolute number of $\mathrm{MCAM}^{+} \mathrm{nTh}$ cells was not calculated because the absolute number of cells in this subset, compared with that in other subsets, was extremely low. Thus, the frequency and the absolute number of $\mathrm{MCAM}^{+} \mathrm{mTh}$ lymphocytes were significantly higher in patients with NMOSD than those in other patients, including patients with MS and NIND (Figure 1, C and D). No difference was observed in either the frequency or the absolute number of cells in each lymphocyte subset between patients with MS and those with MG or NIND. In addition, no correlation between the frequency or the absolute number of $\mathrm{MCAM}^{+}$ cells in each lymphocyte subset and activity or severity of CNS IDDs was observed. Moreover, there was no difference in the frequency and the absolute number of CD $49 \mathrm{~d}^{+}$lymphocytes among the disease groups (data not shown). 

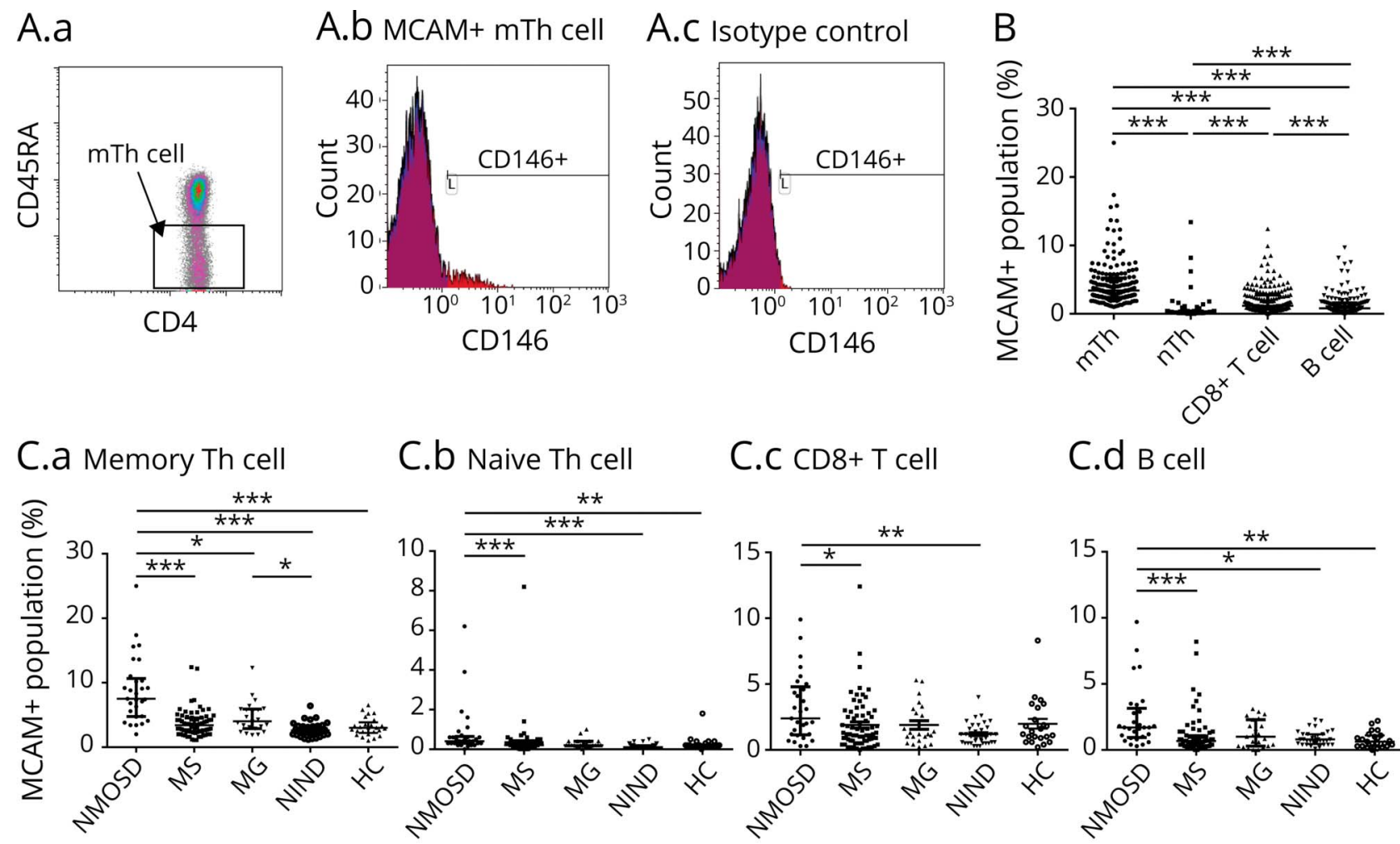

C.C CD8+T cell

C.d B cell
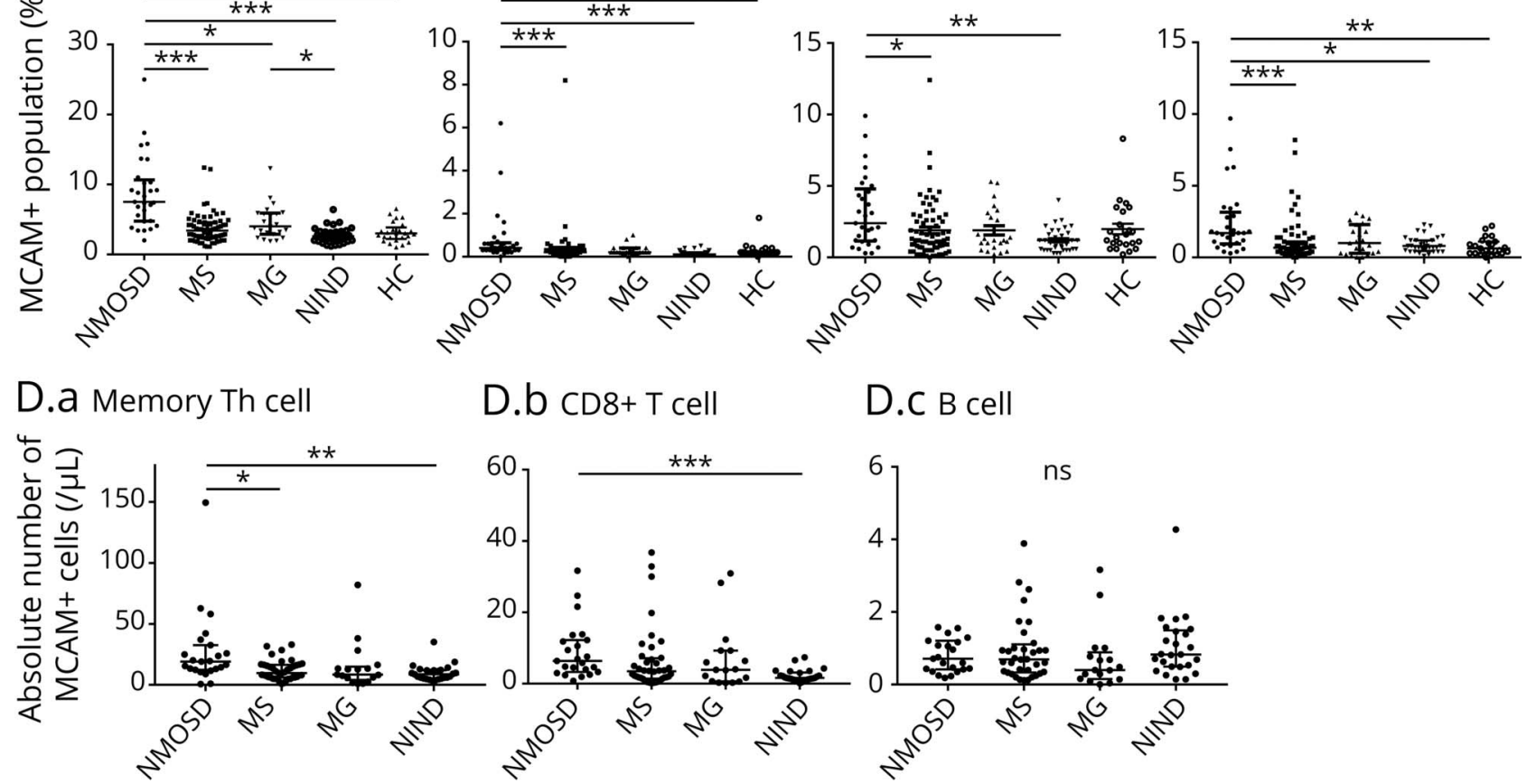

(A.a-A.c) Representative dot plot and histogram of $\mathrm{MCAM}^{+}\left(\mathrm{CD} 146^{+}\right) \mathrm{mTh}$ cells (CD3 ${ }^{+} \mathrm{CD} 4^{+} \mathrm{CD} 45 \mathrm{RA}^{-}$lymphocytes) using flow cytometry. The lymphocyte subsets included mTh cells, $\mathrm{CD}^{+} \mathrm{CD} 4^{+} \mathrm{CD} 45 \mathrm{RA} \mathrm{A}^{-}$lymphocytes; naive helper T cells, $\mathrm{CD} 3^{+} \mathrm{CD} 4^{+} \mathrm{CD} 45 \mathrm{RA} \mathrm{A}^{+}$lymphocytes; $\mathrm{CD} 8^{+} \mathrm{T}$ cells, $\mathrm{CD} 3^{+}$ CD8 ${ }^{+}$lymphocytes; and B cells, CD3 ${ }^{-}$CD19 $9^{+}$lymphocytes. The $\mathrm{MCAM}^{+}\left(\mathrm{CD} 146^{+}\right)$and a4-integrin ${ }^{+}\left(\mathrm{CD} 49 \mathrm{~d}^{+}\right)$populations were defined based on the fluorescence intensity of the isotype control. (B) Frequency of $\mathrm{MCAM}^{+}$cells in all lymphocyte subsets $(n=183: 72$ patients with MS, 29 with NMOSD, 23 with MG, 34 with NIND, and $25 \mathrm{HCs}$ ). (C.a-C.d) Frequency of MCAM ${ }^{+}$cells in all participants (72 patients with MS, 29 with NMOSD, 23 with MG, 34 with NIND, and $25 \mathrm{HCS}$ ). (D.a-D.c) Absolute number of MCAM ${ }^{+}$cells in all patients (40 patients with MS, 23 with NMOSD, 17 with MG, and 26 NIND). Dimethyl fumarate (DMF)- $(n=11)$ and fingolimod- $(n=18)$ treated patients with MS were excluded because treatment with these DMDs reduces the absolute number of lymphocytes. Dots represent individual samples. The lower, upper, and middle lines correspond to the 25th centile, 75th centile, and median, respectively. ${ }^{*} p<0.05, * \star p<0.01$, and $* \star * p<0.001 . \mathrm{HC}=$ healthy control; MCAM = melanoma cell adhesion molecule; MG = myasthenia gravis; $\mathrm{mTh}$ cell = memory helper T cell; NIND = noninflammatory neurologic disorders; NMOSD = neuromyelitis optica spectrum disorder; ns = not significant.

\section{Effect of DMDs or Steroids on the Frequency and Absolute Number of MCAM ${ }^{+}$Lymphocytes in Patients With CNS IDD}

To clarify the effect of DMDs or steroids on $\mathrm{MCAM}^{+-}$ lymphocytes, we examined the frequency and the absolute number of $\mathrm{MCAM}^{+}$lymphocytes between untreated patients with CNS IDD and patients with CNS IDD treated with DMDs or steroids. In FTY-treated patients with MS, the frequencies and absolute numbers of some lymphocyte subsets decreased, as shown in eTables 1 and 2, links.lww.com/NXI/ A559. Although there was no difference in the frequency of $\mathrm{MCAM}^{+}$lymphocytes among the patients treated with different DMDs (Figure $2 \mathrm{~A}$ ), the absolute number of $\mathrm{MCAM}^{+} \mathrm{mTh}$ cells, $\mathrm{CD}^{+} \mathrm{T}$ cells, and $\mathrm{B}$ cells was significantly decreased in FTY-treated patients compared with that in other DMDtreated and untreated patients with MS (Figure 2B). 
Table 2 Definition of Each Lymphocyte Subset

\begin{tabular}{ll}
\hline Lymphocyte subset & Marker \\
\hline Memory helper T cells & $\mathrm{CD}^{+} \mathrm{CD} 4^{+} \mathrm{CD} 45 \mathrm{RA}^{-}$ \\
\hline Naive helper T cells & $\mathrm{CD}^{+} \mathrm{CD} 4^{+} \mathrm{CD} 45 \mathrm{RA}^{+}$ \\
\hline CD8 $^{+}$cytotoxic T cells & $\mathrm{CD}^{+} \mathrm{CD} 8^{+}$ \\
\hline B cells & $\mathrm{CD} 3^{-} \mathrm{CD} 19^{+}$ \\
\hline
\end{tabular}

Although there was no difference in the PSL dosage between patients with NMOSD and MG (mean dosage, 12.3 and 10.6 $\mathrm{mg} /$ day, respectively), a significant difference was observed in the frequency of $\mathrm{MCAM}^{+}$mTh cells between PSL-treated patients with NMOSD and MG $(p<0.05$, Figure $2 \mathrm{C})$. This result suggested that the increase in the frequency of $\mathrm{MCAM}^{+} \mathrm{mTh}$ cells in NMOSD was independent of the effects of the steroid.

\section{$\mathrm{MCAM}^{+} \mathrm{mTh}$ Cells Were Enriched in the CSF of Patients With CNS IDD}

Finally, we examined the frequency and the absolute number of $\mathrm{MCAM}^{+}$lymphocytes in the CSF of patients with
CNS IDD and NIND (Figure 3, A and B). The frequency of CSF MCAM ${ }^{+}$mTh cells was significantly higher in patients with MS and NMOSD than that in those with NIND. As shown in Figure 3A, the difference in the frequency of $\mathrm{MCAM}^{+}$mTh cells between the PB and CSF of patients with MS was significant, whereas that between the $\mathrm{PB}$ and CSF of patients with NMOSD was not significant. Furthermore, the absolute number of CSF $\mathrm{MCAM}^{+} \mathrm{mTh}$ cells and $\mathrm{CD}^{+} \mathrm{T}$ cells was significantly higher in patients with NMOSD than that in patients with NIND (Figure 3B). We speculated that the frequency of $\mathrm{MCAM}^{+} \mathrm{mTh}$ cells in the $\mathrm{PB}$ reflected that of CSF $\mathrm{MCAM}^{+}$mTh cells. Therefore, we examined the correlation between the frequencies of $\mathrm{MCAM}^{+}$mTh cells in the PB and CSF. Although analysis of patients with NMOSD and NIND revealed a strong correlation $\left(\mathrm{r}^{2}=0.91, p<0.001\right.$; Figure $3 \mathrm{C}$, left $)$, the MSindependent analysis showed no significant correlation between these frequencies $\left(\mathrm{r}^{2}=0.22, p>0.05\right.$; Figure $3 \mathrm{C}$, right). Similar to the $\mathrm{PB}$, most of the $\mathrm{MCAM}^{+} \mathrm{mTh}$ cells in the CSF coexpressed CD49d (data not shown). These data suggested that $\mathrm{MCAM}^{+}$mTh cells might contribute to the pathogenesis of both MS and NMOSD through different mechanisms.

Figure 2 Frequency and Absolute Number of MCAM+ Lymphocytes in DMD- or Steroid-Treated Patients With CNS IDD
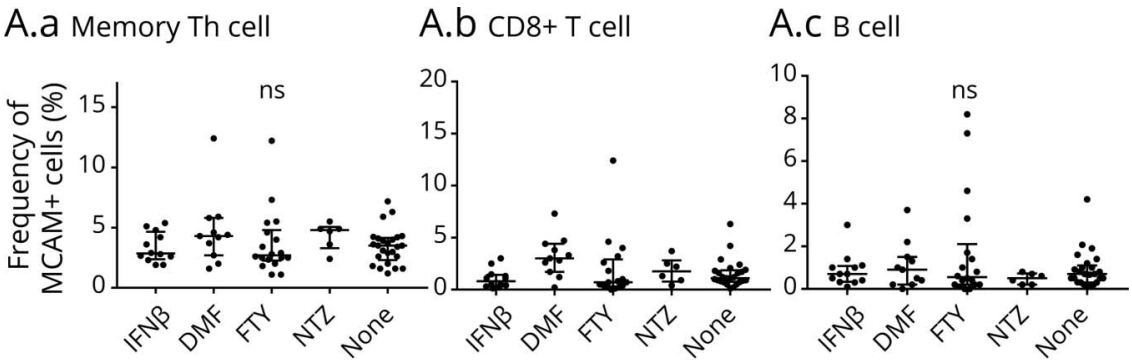

B.a Memory Th cell

B.b cD8+ T cell

B.C B cell
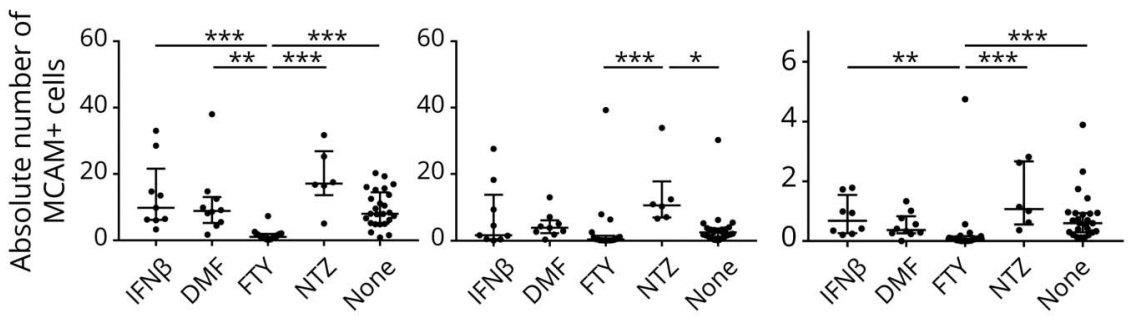

C. Memory Th cell

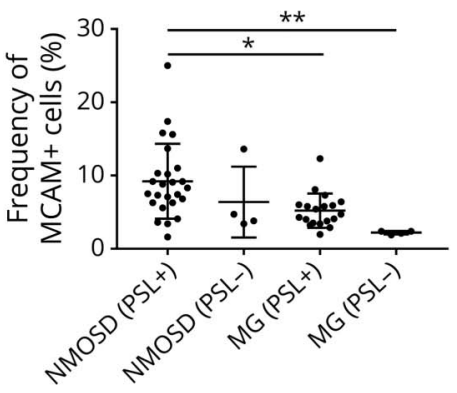

(A.a-A.c) Frequency of MCAM $^{+}$cells in each lymphocyte subset among the DMD- or steroid-treated patients with MS (IFN- $\beta$ [ $n=12]$, DMF $[n=11]$, FTY [ $=18]$, and NTZ [ $=6]$ ) and untreated patients with MS $(n=25)$. (B.a-B.c) Absolute number of $\mathrm{MCAM}^{+}$ cells in each lymphocyte subset among the DMD- or steroid-treated patients with MS (IFN- $\beta$ [ $n=9$ ], DMF $[n=10]$, FTY $[n=18]$, and NTZ [ $n=6]$ ) and untreated patients $(n=24)$. (C) Frequency of $M_{C A M}{ }^{+}$mTh cells in the PB of patients with NMOSD and MG treated with or without PSL. At the time of examination, 25 of the 29 patients with NMOSD and 19 of the 23 patients with MG were undergoing treatment with oral PSL. Dots represent individual samples. The lower, upper, and middle lines correspond to the 25th centile, 75th centile, and median, respectively. ${ }^{\star} p<0.05,{ }^{*} p<<0.01$, and $* * \star p<0.001$. DMD $=$ disease-modifying drug; DMF = dimethyl fumarate; FTY = fingolimod; $I D D=$ inflammatory demyelinating disease; IFN = interferon; $\mathrm{MCAM}=$ melanoma cell adhesion molecule; MG = myasthenia gravis; $\mathrm{mTh}$ cell $=$ memory helper $\mathrm{T}$ cell; $\mathrm{NMOSD}$ = neuromyelitis optica spectrum disorder; $\mathrm{ns}=$ not significant; NTZ = natalizumab; PB = peripheral blood; PSL = prednisolone. 


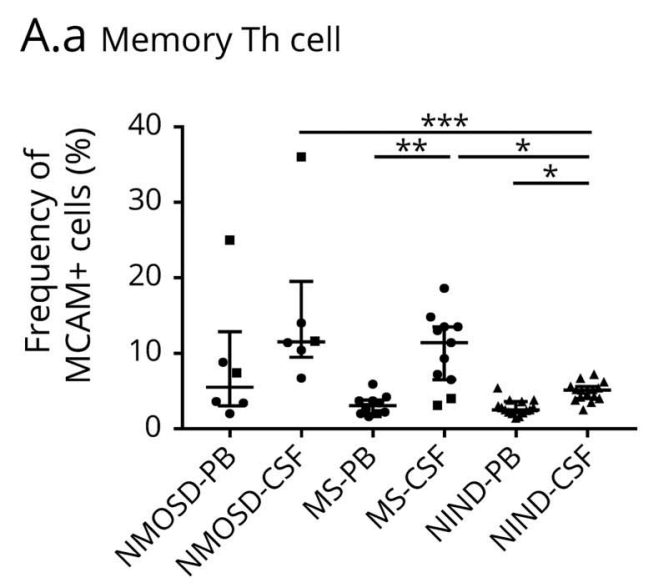

\section{A.b cD8 $+T$ cell}

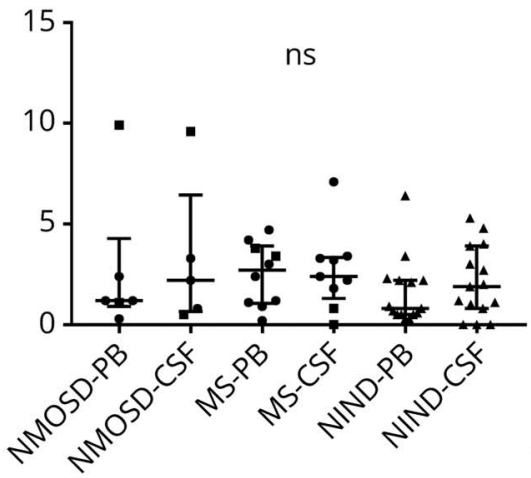

A.C B cell

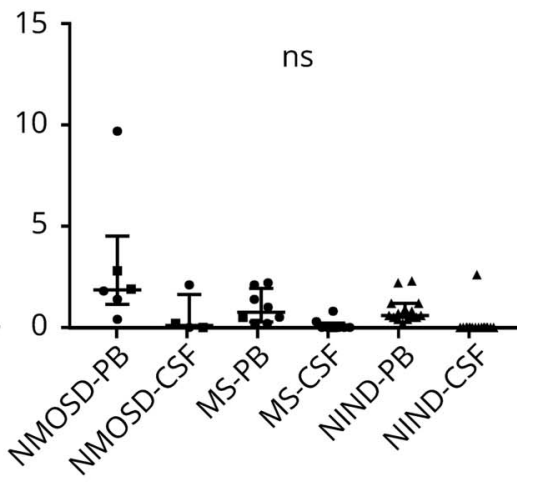

B.a Memory Th cell

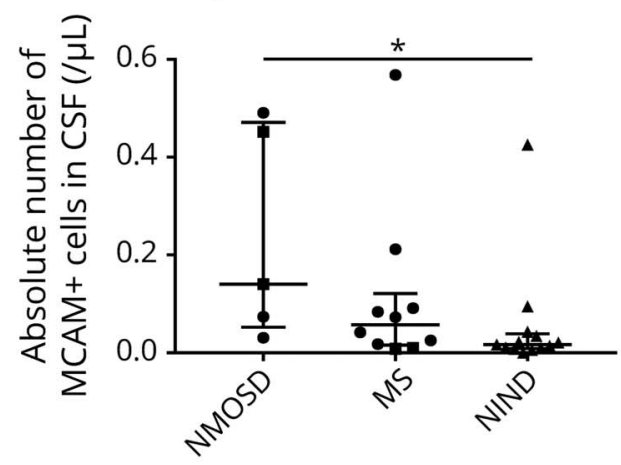

C.a NMOSD, NIND

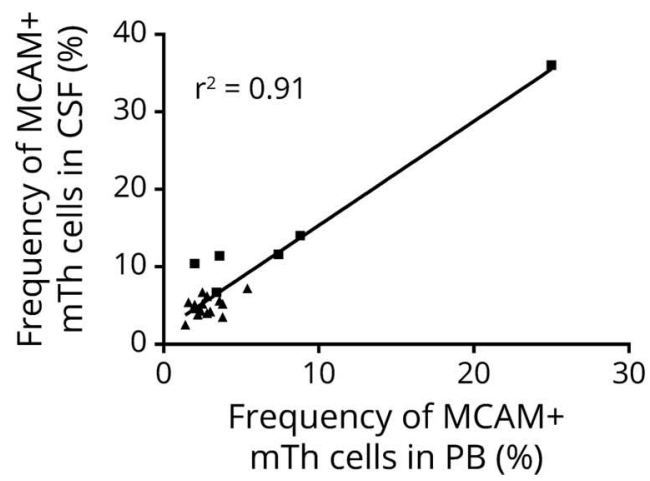

B.b cD8 $+\mathrm{T}$ cell

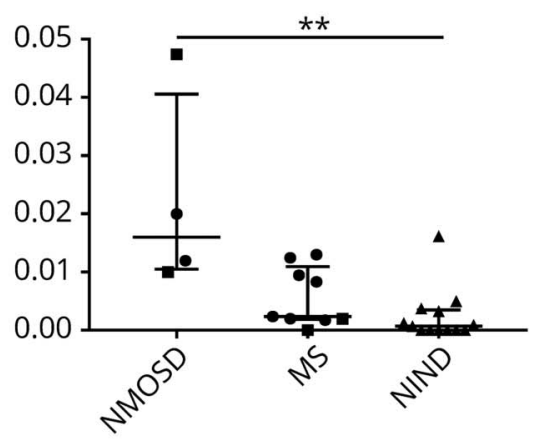

C.b MS

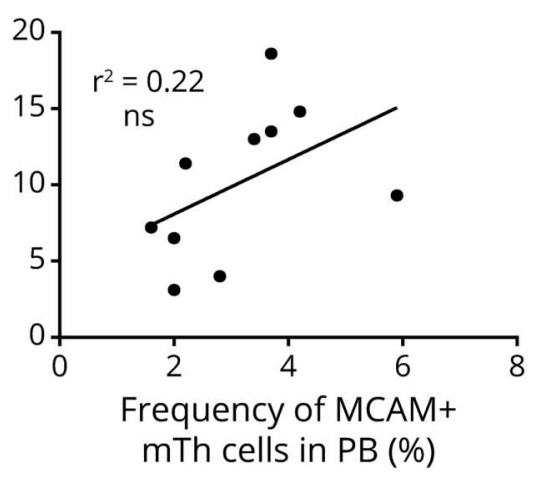

(A.a-A.c) Frequency of CSF and PB MCAM ${ }^{+}$lymphocytes (MS [ $=10$ ], NMOSD [ $=6$ ], and NIND [ $\left.=15\right]$ ). At examination, 8 patients with MS and 4 patients with NMOSD were in the relapse phase. (B.a-B.b) Absolute number of CSF MCAM ${ }^{+}$lymphocytes (MS [ $\left.n=10\right], N M O S D$ [ $\left.n=5\right]$, and NIND [ $\left.n=13\right]$ ). The absolute number of $\mathrm{MCAM}^{+} \mathrm{B}$ cells is not shown in this figure because this subset has been rarely observed in the CSF. Closed circles represent the relapse phase, and closed squares represent the remission phase in (A) and (B). (C) Correlation between the frequencies of PB and CSF MCAM ${ }^{+}$mTh cells in patients with (C.a) $\operatorname{NMOSD}(n=6$, closed square) and $\operatorname{NIND}(n=15$, closed triangle) and (C.b) only in patients with MS ( $n=10$, closed circle). Dots represent individual samples. The lower, upper, and middle lines correspond to the 25th centile, 75th centile, and median, respectively. ${ }^{\star} p<0.05, \star \star p<0.01$, and $\star \star \star *<0.001$. IDD $=$ inflammatory demyelinating disease; MCAM = melanoma cell adhesion molecule; $\mathrm{mTh}$ cell = memory helper $\mathrm{T}$ cell; NIND = noninflammatory neurologic disorders; NMOSD = neuromyelitis optica spectrum disorder; ns = not significant; PB = peripheral blood.

\section{Discussion}

This study was designed to clarify the differences in MCAM expression using lymphocytes from patients with MS and NMOSD. The results showed that in patients with relapsing MS, the frequency of $\mathrm{MCAM}^{+} \mathrm{mTh}$ cells increased only in the CSF, whereas in those with NMOSD, the frequency of $\mathrm{MCAM}^{+} \mathrm{mTh}$ cells increased in both the $\mathrm{PB}$ and CSF.

Adhesion molecules play key roles in MS pathogenesis. a4Integrin is the most important adhesion molecule that is involved in the migration of inflammatory lymphocytes to the CNS. NTZ is a widely used mAb against $\alpha 4$-integrin and one 
of the most effective DMDs used for MS treatment. Although there have been many studies on adhesion molecules in MS, NTZ is the only approved and effective drug that targets adhesion molecules.

MCAM is one of the adhesion molecules that is involved in the migration of lymphocytes to the CNS. ${ }^{12-14,18-20}$ MCAM is found on endothelial cells and $2 \%-3 \%$ of T cells. Laminin-411 is the ligand of MCAM. ${ }^{13,14} \mathrm{MCAM}^{+} \mathrm{T}$ cells have a proinflammatory phenotype; they secrete IL-17, IFN- $\gamma$, granulocyte macrophage-colony-stimulating factor, and granzyme $\mathrm{B} .{ }^{10,11,18}$ The frequency of $\mathrm{PB} \mathrm{MCAM}^{+}$Th cells is increased in rheumatoid arthritis (RA), Behcet disease, and inflammatory bowel diseases, and MCAM expression is correlated with the activity and/or severity of these diseases. ${ }^{8-11}$ Moreover, in RA, $\mathrm{MCAM}^{+}$Th cells accumulate in the synovial fluid, suggesting that $\mathrm{MCAM}^{+}$Th cells can migrate to inflammatory sites from the blood owing to their ability of extravasation through cellcell adhesion. ${ }^{9,21}$

Previous studies have revealed that MCAM is involved in EAE and MS pathogenesis. ${ }^{12-14,17-20} \mathrm{MCAM}^{+}$Th cells have the characteristics of pathogenic Th17 cells, such as the ability to produce both IFN- $\gamma$ and IL-17, and a strong migration capacity. ${ }^{11,12,14,19} \mathrm{MCAM}^{+}$Th cells accumulate in the CSF and CNS lesions of patients with MS. ${ }^{12,17,19}$ Similarly, $\mathrm{MCAM}^{+} \mathrm{CD}^{+} \mathrm{T}$ cells also accumulate in the CSF and CNS lesions of patients with relapsing MS. ${ }^{18}$ Moreover, an MCAM blockade restricted the migration of Th cells and $\mathrm{CD}^{+} \mathrm{T}$ cells from the blood to the CNS in the blood-brain barrier (BBB) model in vitro. ${ }^{12,14,18}$ Even in EAE, an MCAM blockade or depletion reduced the neurologic deficit. ${ }^{12,14,18}$ A previous study reported that the frequency of CSF CD49 $\mathrm{d}^{+}$Th cells decreased, whereas the frequency of $\mathrm{MCAM}^{+} \mathrm{mTh}$ cells increased in patients with MS on longterm NTZ treatment compared with that in those without NTZ treatment, which suggests that $\mathrm{MCAM}^{+} \mathrm{mTh}$ cell adhesion is not affected by NTZ alone. ${ }^{19}$ According to the results of previous studies, MCAM is involved in the pathogenesis of MS and EAE; however, studies on the role of MCAM in the pathogenesis of CNS IDDs are limited.

Contrary to our speculation and the results of previous studies, ${ }^{12,17}$ the frequency of $\mathrm{MCAM}^{+} \mathrm{mTh}$ cells and $\mathrm{CD} 8^{+}$ $\mathrm{T}$ cells was not increased in the PB of patients with MS. With regard to the CSF analysis, the frequency of $\mathrm{MCAM}^{+} \mathrm{mTh}$ cells in the CSF was higher in the relapse phase $(\mathrm{n}=8$, mean frequency of $10.5 \%)$ than that in the remission phase $(\mathrm{n}=2$, mean frequency of 3.6\%, Figure 3A). Although the number of patients was small, this finding suggests that the frequency of CSF $\mathrm{MCAM}^{+} \mathrm{mTh}$ cells might be a biomarker of disease activity in patients with MS. Of interest, several studies have shown that the frequency of Th17 cells is increased in the CSF of patients with active MS. ${ }^{22-25}$ Moreover, as well as $\mathrm{MCAM}^{+}$Th cells, previous reports have indicated that CSF-accumulating Th17 cells also showed characteristics of pathogenic Th17 cells, and the frequency of this subset did not increase in the PB. ${ }^{22,25}$
These findings suggest that pathogenic Th17 cells do not necessarily increase in both the PB and CSF.

We speculated that, at first, an unknown cause, such as a genetic and/or environmental factor (viral infection, smoking, and low sun exposure), triggered autoimmune activation and induced BBB damage (or increased BBB permeability) in patients with MS. ${ }^{1,2,26-29}$ Subsequently, pathogenic lymphocytes, such as $\mathrm{MCAM}^{+} \mathrm{mTh}$ cells, migrated from the PB to the CSF and the CNS, owing to their strong migration capacity, ${ }^{10-13,19,21}$ without a quantitative change in the PB. Then, inflammatory demyelination occurred. Unlike in MS, the frequency and the absolute number of $\mathrm{MCAM}^{+}$lymphocytes (especially $\mathrm{mTh}$ cells) increased in both the PB and CSF in NMOSD. Thus, we speculated that the activation of MCAM-related pathogenic Th17 cell autoimmunity occurred not only in the CNS but also systemically, including in the PB in NMOSD, with a quantitative change in the $\mathrm{PB}$. Our speculation is supported by previous studies in which more patients with NMOSD than those with MS tend to present with comorbid autoimmune disorders, such as systemic lupus erythematosus, Sjögren syndrome, MG, and autoimmune thyroid diseases. ${ }^{16,30}$ Moreover, Th17 cellrelated pathogenic autoimmunity has been shown in patients with NMOSD. ${ }^{31-34}$ A previous study demonstrated that AQP4specific $T$ cells in the PB of patients with NMOSD exhibited a Th17 bias that promoted neutrophil infiltration through IL$17 .{ }^{31}$ In addition, a meta-analysis showed that the proportion of PB Th17 cells was higher in patients with NMOSD than that in those with MS and/or in controls. ${ }^{33}$ Therefore, we speculated that these previously reported Th17 cells in NMOSD included $\mathrm{MCAM}^{+}$Th cells.

In this study, there was no difference in the frequencies of $\mathrm{MCAM}^{+}$lymphocytes in patients with MS treated with different DMDs. However, although the number of patients treated with DMDs was small, the absolute number of $\mathrm{MCAM}^{+-}$ lymphocytes was significantly lower in FTY-treated patients with MS than that in other DMD-treated or untreated patients with MS (Figure 2B). FTY is a sphingosine-1-phosphate (S1P) modulator that binds to the S1P receptor. This results in the sequestration of $\mathrm{T}$ cells and $\mathrm{B}$ cells in the lymph nodes; there is a reduction in the number of $\mathrm{PB}$ lymphocytes, and the migration of the lymphocytes from the PB to the CNS is inhibited. ${ }^{35-37}$ This study partly explains the mechanism underlying the therapeutic effects of FTY, inhibiting the migration of $\mathrm{MCAM}^{+-}$ lymphocytes from the $\mathrm{PB}$ to the CNS. Other DMDs are effective in suppressing the disease activity; however, they do not reduce the number of $\mathrm{PB} \mathrm{MCAM}^{+}$lymphocytes. NTZ binds the a4-integrin subunit expressed on the lymphocyte and prevents the migration of the lymphocyte into the $\mathrm{CNS}^{7}$; however, NTZ does not decrease the number of peripheral lymphocytes. ${ }^{38}$ Therefore, the results from this study are consistent with that for the mechanism of action for NTZ. The mechanisms for IFN- $\beta$ and DMF are less understood. ${ }^{36,37}$ IFN- $\beta$ does not change the frequency and the absolute number of Th17 cells; however, IFN- $\beta$ inhibits the Th17 axis and enhances the production of anti-inflammatory cytokines such as 
IL-10 and IL-4. ${ }^{36,39}$ Therefore, it is understandable that IFN- $\beta$ suppresses the disease activity without decreasing the number of $\mathrm{MCAM}^{+}$lymphocytes. Similar to FTY, DMF reduces the PB lymphocytes, including the Th17 cells. ${ }^{36,38}$ In this study, the frequency and the absolute number of $\mathrm{MCAM}^{+}$lymphocytes were unaltered in patients treated with DMF. One of the reasons could be the lack of effect on the MCAM expression in the lymphocytes. The small number of patients treated with DMF and/or the duration of DMF treatment in this study could also have contributed to this effect. Despite the lack of effects on the frequency and the number of $\mathrm{MCAM}^{+}$lymphocytes, DMF could modulate the function of $\mathrm{MCAM}^{+}$lymphocytes through mechanisms such as the upregulation of the nuclear factor erythroid-derived 2-related antioxidant pathway and the inhibition of the nuclear factor- $\mathrm{kB}$ translocation. ${ }^{40}$

There are certain limitations in this study. First, we used cryopreserved PBMC and CSF samples; cryopreservation may result in the modification of the expression of MCAM. Of note, for consistency, we analyzed the expression of MCAM using cryopreserved samples from all patients. Second, the number of patients treated with DMDs was small and, therefore, not enough to speculate a relationship between DMDs and MCAM expression. Third, the number of patients with NMOSD and MG without steroid therapy was small. Thus, the possibility of the effects of steroid on MCAM expression must be considered. However, the frequency of $\mathrm{MCAM}^{+} \mathrm{mTh}$ cells was significantly higher in PSL-treated patients with NMOSD than that in PSL-treated patients with MG, although there was no difference in PSL dosage between the groups. Therefore, we considered that the activation of MCAM-related Th17 cell autoimmunity occurred in both the periphery and the CNS in patients with NMOSD.

In conclusion, this study showed that $\mathrm{MCAM}^{+} \mathrm{mTh}$ cells were elevated in only the CSF of relapsing patients with MS but in the PB and CSF of patients with NMOSD. These results suggest that $\mathrm{MCAM}^{+}$Th17 cells contribute to the pathogenesis of both MS and NMOSD through different mechanisms. These findings suggest that MCAM could be a therapeutic target and biomarker of CNS IDDs, and further research is needed to elucidate the detailed role and underlying mechanism of MCAM expression in CNS IDD pathogenesis.

\section{Acknowledgment}

The authors thank Dr. Toshiyuki Takahashi (Department of Neurology, Tohoku University, Japan) for analyzing the antiAQP4 and anti-MOG antibodies and Michiyo Ohara (Department of Neurology, Tokyo Women's Medical University, Tokyo, Japan) for her technical support and expertise.

\section{Study Funding}

This work was supported in part by the Health and Labour Sciences Research Grant on Intractable Diseases (Neuroimmunological Diseases) from the Ministry of Health, Labour and Welfare of Japan (20FC1030).

\section{Disclosure}

A. Kondo, N. Kanda, H. So, H. Kojima, and K. Kitagawa report no disclosures relevant to the manuscript. R. Ikeguchi received honoraria for talks from Alexion Pharmaceuticals, Chugai Pharmaceutical Co, Ltd, and Novartis Pharma. Y. Shimizu received honoraria for talks from Alexion Pharmaceuticals, Bayer Yakuhin, and Chugai Pharmaceutical Co, Ltd; and personal compensation for consulting services from Biogen Idec Japan, Teijin Pharma, and Novartis Pharma.

\section{Publication History}

Received by Neurology: Neuroimmunology \& Neuroinflammation February 5, 2021. Accepted in final form July 21, 2021.

\begin{tabular}{|c|c|c|}
\hline Name & Location & Contribution \\
\hline $\begin{array}{l}\text { Ryotaro } \\
\text { Ikeguchi, } \\
\text { MD, PhD }\end{array}$ & $\begin{array}{l}\text { Tokyo Women's } \\
\text { Medical University, } \\
\text { Japan }\end{array}$ & $\begin{array}{l}\text { Design and conceptualized the } \\
\text { study; data collection; analyzed data; } \\
\text { and drafting the manuscript for } \\
\text { intellectual content }\end{array}$ \\
\hline $\begin{array}{l}\text { Yuko } \\
\text { Shimizu, MD, } \\
\text { PhD }\end{array}$ & $\begin{array}{l}\text { Tokyo Women's } \\
\text { Medical University, } \\
\text { Japan }\end{array}$ & $\begin{array}{l}\text { Design and conceptualized the } \\
\text { study; data collection; analyzed data; } \\
\text { and drafting the manuscript for } \\
\text { intellectual content }\end{array}$ \\
\hline $\begin{array}{l}\text { Akihiro } \\
\text { Kondo, MD }\end{array}$ & $\begin{array}{l}\text { Tokyo Women's } \\
\text { Medical University, } \\
\text { Japan }\end{array}$ & Data collection and analyzed data \\
\hline $\begin{array}{l}\text { Natsuki } \\
\text { Kanda, MD }\end{array}$ & $\begin{array}{l}\text { Tokyo Women's } \\
\text { Medical University, } \\
\text { Japan }\end{array}$ & Data collection and analyzed data \\
\hline $\begin{array}{l}\text { Hayato So, } \\
\text { MD }\end{array}$ & $\begin{array}{l}\text { Tokyo Women's } \\
\text { Medical University, } \\
\text { Japan }\end{array}$ & Data collection and analyzed data \\
\hline $\begin{array}{l}\text { Haruka } \\
\text { Kojima, MD }\end{array}$ & $\begin{array}{l}\text { Tokyo Women's } \\
\text { Medical University, } \\
\text { Japan }\end{array}$ & Data collection and analyzed data \\
\hline $\begin{array}{l}\text { Kazuo } \\
\text { Kitagawa, } \\
\text { MD, PhD }\end{array}$ & $\begin{array}{l}\text { Tokyo Women's } \\
\text { Medical University, } \\
\text { Japan }\end{array}$ & $\begin{array}{l}\text { Drafting and revision of the } \\
\text { manuscript }\end{array}$ \\
\hline
\end{tabular}

\section{References}

1. McFarland HF, Martin R. Multiple sclerosis: a complicated picture of autoimmunity. Nat Immunol. 2007;8(9):913-919.

2. Dendrou CA, Fugger L, Friese MA. Immunopathology of multiple sclerosis. Nat Rev Immunol. 2015;15(9):545-558.

3. Panitch HS, Hirsch RL, Schindler J, Johnson KP. Treatment of multiple sclerosis with gamma interferon: exacerbations associated with activation of the immune system. Neurology. 1987;37(7):1097-1102.

4. Tzartos JS, Friese MA, Craner MJ, et al. Interleukin-17 production in central nervous system-infiltrating $\mathrm{T}$ cells and glial cells is associated with active disease in multiple sclerosis. Am J Pathol. 2008;172(1):146-155.

5. Kebir H, Ifergan I, Alvarez JI, et al. Preferential recruitment of interferon-gammaexpressing TH17 cells in multiple sclerosis. Ann Neurol. 2009;66(3):390-402.

6. Kaskow BJ, Baecher-Allan C. Effector T cells in multiple sclerosis. Cold Spring Harb Perspect Med. 2018;8(4):a029025.

7. Havrdova E, Galetta S, Hutchinson M, et al. Effect of natalizumab on clinical and radiological disease activity in multiple sclerosis: a retrospective analysis of the Natalizumab safety and efficacy in relapsing-remitting multiple sclerosis (AFFIRM) study. Lancet Neurol. 2009;8(3):254-260.

8. Bardin N, Reumaux D, Geboes K, et al. Increased expression of CD146, a new marker of the endothelial junction in active inflammatory bowel disease. Inflamm Bowel Dis. 2006;12(1):16-21. 
9. Dagur PK, Tatlici G, Gourley M, et al. CD146+ T lymphocytes are increased in both the peripheral circulation and in the synovial effusions of patients with various musculoskeletal diseases and display pro-inflammatory gene profiles. Cytometry B Clin Cytom. 2010;78(2):88-95.

10. Dagur PK, Biancotto A, Wei L, et al. MCAM-expressing CD4(+) T cells in peripheral blood secrete IL-17A and are significantly elevated in inflammatory autoimmune diseases. J Autoimmun. 2011;37(4):319-327.

11. Dagur PK, McCoy JP Jr. Endothelial-binding, proinflammatory T cells identified by MCAM (CD146) expression: characterization and role in human autoimmune diseases. Autoimmun Rev. 2015;14(5):415-422.

12. Larochelle $\mathrm{C}$, Cayrol R, Kebir H, et al. Melanoma cell adhesion molecule identifies encephalitogenic $\mathrm{T}$ lymphocytes and promotes their recruitment to the central nervous system. Brain. 2012;135(Pt 10):2906-2924.

13. Breuer J, Korpos E, Hannocks MJ, et al. Blockade of MCAM/CD146 impedes CNS infiltration of T cells over the choroid plexus. J Neuroinflammation. 2018;15(1):236.

14. Flanagan K, Fitzgerald K, Baker J, et al. Laminin- 411 is a vascular ligand for MCAM and facilitates TH17 cell entry into the CNS. Plos One. 2012;7(7):e40443.

15. Polman CH, Reingold SC, Banwell B, et al. Diagnostic criteria for multiple sclerosis: 2010 revisions to the McDonald criteria. Ann Neurol. 2011;69(2):292-302.

16. Wingerchuk DM, Banwell B, Bennett JL, et al. International consensus diagnostic criteria for neuromyelitis optica spectrum disorders. Neurology. 2015;85(2):177-189.

17. Petersen ER, Ammitzbøll C, Søndergaard HB, et al. Expression of melanoma cell adhesion molecule-1 (MCAM-1) in natalizumab-treated multiple sclerosis. J Neuroimmunol. 2019; 337:577085.

18. Larochelle C, Lécuyer MA, Alvarez JI, et al. Melanoma cell adhesion molecule-positive CD8 T lymphocytes mediate central nervous system inflammation. Ann Neurol. 2015, 78(1):39-53.

19. Schneider-Hohendorf T, Rossaint J, Mohan H, et al. VLA-4 blockade promotes differential routes into human CNS involving PSGL-1 rolling of T cells and MCAMadhesion of TH17 cells. J Exp Med. 2014;211(9):1833-1846.

20. Cayrol R, Kebir H, Iferg. an I, et al. MCAM/CD146 is expressed by brain endothelial cells and defines a unique effector memory lymphocyte subset involved in neuroinflammation. Clin Immunol. 2009;131(suppl S12):OR21.

21. Guezguez B, Vigneron P, Lamerant N, Kieda C, Jaffredo T, Dunon D. Dual role of melanoma cell adhesion molecule (MCAM)/CD146 in lymphocyte endothelium interaction: MCAM/CD146 promotes rolling via microvilli induction in lymphocyte and is an endothelial adhesion receptor. J Immunol. 2007;179(10):6673-6685.

22. Brucklacher-Waldert V, Stuerner K, Kolster M, Wolthausen J, Tolosa E. Phenotypical and functional characterization of T helper 17 cells in multiple sclerosis. Brain. 2009; 132(Pt 2):3329-3341

23. Ghezzi L, Cantoni C, Cignarella F, et al. T cells producing GM-CSF and IL-13 are enriched in the cerebrospinal fluid of relapsing MS patients. Mult Scler. 2019;26(10):1171-1186.

24. Kunkl M, Frascolla S, Amormino C, Volpe E, Tuosto L. T helper cells: the modulators of inflammation in multiple sclerosis. Cells. 2020;9(2):482.
25. van Langelaar J, van der Vuurst de Vries RM, Janssen M, et al. T helper 17.1 cells associate with multiple sclerosis disease activity: perspectives for early intervention. Brain. 2018;141(5):1334-1349.

26. Waubant E, Lucas R, Mowry E, et al. Environmental and genetic risk factors for MS: an integrated review. Ann Clin Transl Neurol. 2019;6(9):1905-1922.

27. Lassmann H. Pathogenic mechanisms associated with different clinical courses of multiple sclerosis. Front Immunol. 2018;9:3116.

28. Casiraghi C, Dorovini-Zis K, Horwitz MS. Epstein-Barr virus infection of human brain microvessel endothelial cells: a novel role in multiple sclerosis. J Neuroimmunol. 2011; 230(1-2):173-177.

29. Ransohoff RM. Immunology: in the beginning. Nature. 2009;462(7269):41-42.

30. Shahmohammadi S, Doosti R, Shahmohammadi A, et al. Autoimmune diseases associated with neuromyelitis optica spectrum disorders: a literature review. Mult Scler Relat Disord. 2019;27:350-363.

31. Varrin-Doyer M, Spencer CM, Schulze-Topphoff U, et al. Aquaporin 4-specific T cells in neuromyelitis optica exhibit a Th17 bias and recognize Clostridium ABC transporter. Ann Neurol. 2012;72(1):53-64.

32. Kaneko K, Sato DK, Nakashima I, et al. CSF cytokine profile in MOG-IgG+ neurological disease is similar to AQP4-IgG+ NMOSD but distinct from MS: a crosssectional study and potential therapeutic implications. J Neurol Neurosurg Psychiatry. 2018;89(9):927-936.

33. Hou MM, Li YF, He LL, et al. Proportions of Th17 cells and Th17-related cytokines in neuromyelitis optica spectrum disorders patients: a meta-analysis. Int Immuno pharmacol. 2019;75:105793.

34. Lucchinetti CF, Guo Y, Popescu BF, Fujihara K, Itoyama Y, Misu T. The pathology of an autoimmune astrocytopathy: lessons learned from neuromyelitis optica. Brain Pathol. 2014;24(1):83-97.

35. Brinkmann V, Billich A, Baumruker T, et al. Fingolimod (FTY720): discovery and development of an oral drug to treat multiple sclerosis. Nat Rev Drug Discov. 2010; 9(11):883-897.

36. Moser T, Akgün K, Proschmann U, Sellner J, Ziemssen T. The role of TH17 cells in multiple sclerosis: therapeutic implications. Autoimmun Rev. 2020;19(10): 102647.

37. McGinley MP, Goldschmidt CH, Rae-Grant AD. Diagnosis and treatment of multiple sclerosis: a review. JAMA. 2021;325(8):765-779.

38. Mills EA, Mao-Draayer Y. Aging and lymphocyte changes by immunomodulatory therapies impact PML risk in multiple sclerosis patients. Mult Scler. 2018;24(8) 1014-1022.

39. Manfredonia F, Pasquali L, Dardano A, Iudice A, Murri L, Monzani F. Review of the clinical evidence for interferon beta 1a (Rebif) in the treatment of multiple sclerosis. Neuropsychiatr Dis Treat. 2008;4(2):321-336.

40. Hosseini A, Masjedi A, Baradaran B, et al. Dimethyl fumarate: regulatory effects on the immune system in the treatment of multiple sclerosis. J Cell Physiol. 2019;234(7): 9943-9955. 


\title{
Neurology \\ Neuroimmunology \& Neuroinflammation
}

\author{
Melanoma Cell Adhesion Molecule Expressing Helper T Cells in CNS Inflammatory \\ Demyelinating Diseases \\ Ryotaro Ikeguchi, Yuko Shimizu, Akihiro Kondo, et al. \\ Neurol Neuroimmunol Neuroinflamm 2021;8; \\ DOI 10.1212/NXI.0000000000001069
}

This information is current as of August 24, 2021

Updated Information \&

Services

References

Subspecialty Collections

Permissions \& Licensing

Reprints including high resolution figures, can be found at:

http://nn.neurology.org/content/8/6/e1069.full.html

This article cites 40 articles, 4 of which you can access for free at: http://nn.neurology.org/content/8/6/e1069.full.html\#\#ref-list-1

This article, along with others on similar topics, appears in the following collection(s):

Multiple sclerosis

http://nn.neurology.org//cgi/collection/multiple_sclerosis

Information about reproducing this article in parts (figures,tables) or in its entirety can be found online at:

http://nn.neurology.org/misc/about.xhtml\#permissions

Information about ordering reprints can be found online: http://nn.neurology.org/misc/addir.xhtml\#reprintsus

Neurol Neuroimmunol Neuroinflamm is an official journal of the American Academy of Neurology.

Published since April 2014, it is an open-access, online-only, continuous publication journal. Copyright

Copyright (C) 2021 The Author(s). Published by Wolters Kluwer Health, Inc. on behalf of the American

Academy of Neurology.. All rights reserved. Online ISSN: 2332-7812.

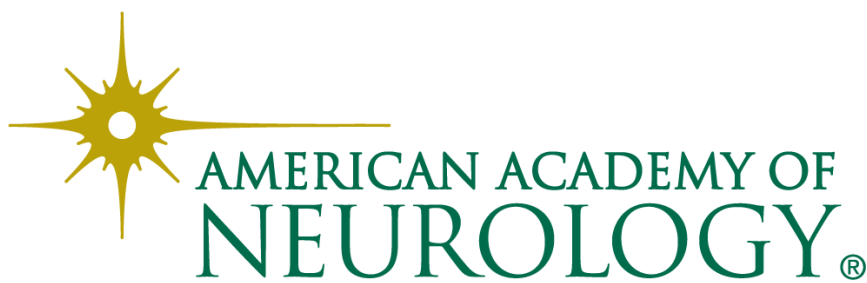

